\title{
COVID-19: uma pandemia que alerta à população
}

Erivan de Souza Oliveira'

Arlandia Cristina Lima Nobre de Morais ${ }^{1}$

Em dezembro de 2019 houve o primeiro caso da síndrome respiratória aguda grave coronavírus 2 (SARSCoV-2) em Wuhan, China [1]. Recentemente denominada pela Organização Mundial da Saúde (OMS) de covid-19 (doença de coronavírus 2019) [2]. Desde então, mais de 27 países confirmaram casos de covid-19, inclusive o Brasil [1]. Devido a rápida disseminação do vírus em 11 de março de 2020, a OMS declarou uma pandemia [3].

Segundo Zhang et al. [1] mais de 2.800 óbitos foram confirmados até 27 de fevereiro de 2020. E esses valores tem aumentado cada vez mais, atualmente são 803.313 casos confirmados mundialmente, sendo 601.362 casos ativos, 162.937 casos recuperados e 39.014 casos fatais, até 31 de março de 2020 [4].

Esse aumento na mortalidade se deve principalmente pelo fato do vírus causar dificuldade respiratória aguda grave, podendo ocasionar infecções que podem levar a pneumonia viral [5]. Trabalhos publicados recentemente enfatizam que o SARS-CoV-2 se liga às células alvo dos hospedeiros através do domínio peptidase da enzima conversora de angiotensina 2 (ECA2), o que facilita a sua entrada e replicação $[1,6,7]$.

O vírus da covid-19 pertence a ordem dos Nidovirales da família Coronaviridae [1]. Pesquisas realizadas por Li et al. [8] e Lau at al. [9] destacaram que os morcegos-ferradura chineses e, subsequentemente, outros morcegos-ferradura são os reservatórios natural desse grupo de vírus, podendo lançar o vírus do tipo SARSCoV que pertence a mesma família do SARS-CoV-2. No entanto, atualmente, ainda não se sabe a real origem e os possíveis vetores intermediários da SARS-CoV-2, bem como o mecanismo exato. Benvenuto et al. [9] destaca que através de uma análise filogenética foi possível encontrar uma origem de morcego para o SARS-CoV-2. Ele ainda menciona que este vírus está relacionado apenas ao coronavírus específico do tipo SARS de morcego isolado de Rhinolophus sinicus em 2015 na China.

Ressalta-sequeatravés do primeirosequenciamento do genoma completo do SARS-CoV-2 na região Norte do Brasil, realizado por pesquisadores do Instituto Leônidas \& Maria Deane (ILMD/Fiocruz Amazônia), foi possível observar que as análises iniciais mostraram nove mutações do vírus em relação à amostra original de Wuhan na China [10].

Diversos estudos publicados em revistas internacionais $[1,11-13]$ reportaram que as comorbidades mais prevalente dos pacientes com covid-19 são hipertensão e diabetes, que frequentemente realizam o tratamento com inibidores da enzima conversora de angiotensina (ECA). Destaca-se que a grande maioria desses pacientes são idosos e fazem parte do grupo de risco da doença.

De acordo com Fang et al. [14] os pacientes que possuem diabetes do tipo 1 ou tipo 2 e/ou hipertensão, que são tratados com inibidores da ECA e/ou bloqueadores

1 Universidade de Fortaleza, Curso de Farmácia. Av. Washington Soares, 1321, Edson Queiroz, 60811-905, Fortaleza, CE, Brasil. Correspondência para: ES OLIVEIRA. E-mail: <erivan@edu.unifor.br>.

Como citar este artigo / How to cite this article

Oliveira ES, Morais ACLN. COVID-19: uma pandemia que alerta à população. InterAm J Med Health 2020;3:e202003008. 
dos receptores da angiotensina II tipo I (BRA), possuem um aumento considerável na expressão dos receptores da ECA2, podendo facilitar a entrada do vírus. Os mesmos autores reportam que os pacientes que utilizam esses medicamentos podem desenvolver covid-19 grave e fatal. Tendo como sugestão o uso dos bloqueadores antihipertensivos dos canais de cálcio para um tratamento alternativo adequado.

Destaca-se que outros estudos vêm questionando o uso do ibuprofeno em pacientes com a covid-19, visto que poderia piorar a condição de saúde $[15,16]$. Day [16] reporta que os especialistas da área de saúde recomendam o uso de paracetamol (se o paciente não for alérgico) como primeira escolha em vez de ibuprofeno e outros anti-inflamatórios não esteroides (AINEs) para tratar os sintomas de febre e dor de garganta, devido ao perfil de segurança do medicamento. Contudo, vale ressaltar que a OMS [17] liberou o uso do ibuprofeno para pacientes com a covid-19.

Neste contexto, pela falta de medicamentos eficaz no tratamento da covid-19, em 27 de março de 2020 o Ministério da Saúde liberou o uso da cloroquina ou hidroxicloroquina como terapia adjuvante no tratamento de formas graves do covid-19 em pacientes hospitalizados com base na Lei n. 13.979 de 06 de fevereiro de 2020 [18].

De acordo com o Ministério da Saúde [18] a dose recomendada da cloroquina no primeiro dia de tratamento é de três comprimidos de $150 \mathrm{mg}$ duas vezes ao dia (dose de ataque $900 \mathrm{mg}$ ), seguido de três comprimidos de $150 \mathrm{mg}$ uma vez ao dia no segundo, terceiro, quarto e quinto dia de tratamento (dose diária $450 \mathrm{mg}$ ). Para a hidroxicloroquina é recomendada a utilização de um comprimido de $400 \mathrm{mg}$ duas vezes ao dia no primeiro dia de tratamento (dose ataque $800 \mathrm{mg}$ ), seguido de um comprimido de $400 \mathrm{mg}$ uma vez ao dia no segundo, terceiro, quarto e quinto dia de tratamento (dose diária $400 \mathrm{mg}$ ).

Segundo Gautret et al. [6] a associação da hidroxicloroquina com azitromicina demonstrou resultados promissores, visto que $70 \%$ dos pacientes do grupo que estavam em tratamento não apresentou carga viral detectável após 6 dias de tratamento. Entretanto, devemos ter em mente que estes medicamentos devem ser utilizados cuidadosamente, principalmente a azitromicina por ser um antimicrobiano e o uso indiscriminado pode provocar resistência bacteriana. Além do uso da cloroquina que pode provocar aumento no intervalo QT, retinopatia e distúrbios cardiovasculares [19]. Cabe frisar que a hidroxicloroquina em uso prolongado é melhor do que a cloroquina, pois permite a utilização de doses mais altas e possui poucas interações com outros medicamentos [6].

É de suma importância discutir o uso destes medicamentos em pacientes que receberam o diagnóstico de covid-19. Desta forma, os profissionais de saúde devem analisar criteriosamente cada paciente tendo em vista a fisiopatologia da doença e os fatores associados, e sempre se questionar: qual é a melhor opção de tratamento?, esses pacientes podem fazer o uso destes medicamentos?, os fins justificam os meios?. Por outro lado, precisamos ter a consciência que os profissionais de saúde estão extremamente cansados e exaustos e vulneráveis ao risco desenvolver a doença ou se tornarem vetores da infecção.

Atualmente, no Brasil, o teste para covid-19 está sendo realizado somente em pacientes mais graves, o que oculta a real situação do país, visto que a estimativa de casos não é exata.

Por isso, os governantes precisam realizar medidas mais rigorosas para conter a pandemia presente no mundo. Apesar das medidas já estabelecidas, o surto da doença está em constante evolução e sobrecarregando os hospitais.

Embora o diagnóstico imediato e o isolamento dos pacientes sejam as principais medidas do controle desse vírus, deve-se avaliar a hipótese da elaboração de um plano de ação de vigilância mais rigorosa, identificar um possível marcador para avaliar o quadro clínico dos pacientes, desenvolver estudos adicionais para compreendermos quais os fatores envolvidos no agravamento dos casos e óbitos que não fazem parte do grupo risco (que desenvolvem as formas graves da doença) devido a faixa etária, por ser imunocompetentes e não possuir doenças preexistentes que são fatores determinantes para a progressão da doença. Além da realização de pesquisas sobre os efeitos dos AINEs em pacientes com a covid-19.

Por fim, espera-se que o número de casos e óbitos causados por essa doença reduzam drasticamente. 


\section{REFERÊNCIAS}

1. Zhang $H$, Penninger JM, Li $Y$, Zhong $N$, Slutsky AS. Angiotensin-converting enzyme 2 (ACE2) as a SARSCoV-2 receptor: molecular mechanisms and potential therapeutic target. Intensive Care Med. 2020; 46:586590 doi: 10.1007/s00134-020-05985-9.

2. Zhang JJ, Dong $X$, Cao $Y Y$, Yuan $Y D$, Yang $Y B$, Yan $Y Q$, et al. Clinical characteristics of 140 patients infected by SARS-CoV-2 in Wuhan, China. Allergy. 2020. [Online ahead of print] doi:10.1111/all.14238

3. Organização Pan-Americana da Saúde (OPAS) [homepage na internet]. OMS afirma que COVID-19 é agora caracterizada como pandemia [acesso em 27 mar 2020]. Disponível em: https://www.paho.org/bra/index. php?option=com_content $\&$ view $=$ article $\& i d=6120$ :oms afirma-que-covid-19-e-agora-caracterizada-comopandemia\&ltemid $=812$

4. Bing [homepage na internet]. Rastreador de COVID-19 [acesso em 29 mar 2020]. Disponível em: https://bing. com/covid

5. Driggin E, Madhavan MV, Bikdeli B, Chuich T, Laracy J, Bondi-Zoccai G, et al. Cardiovascular Considerations for Patients, Health Care Workers, and Health Systems During the Coronavirus Disease 2019 (COVID-19) Pandemic. J Am Coll Cardiol 2020 Mar 18 [Online ahead of print]. doi: 10.1016/j.jacc.2020.03.031.

6. Gautret P, Lagier JC, Parola P, Hoang VT, Meddeb L, Mailhe $M$, et al. Hydroxychloroquine and azithromycin as a treatment of COVID-19: results of an open-label nonrandomized clinical trial. J Pre-proof. 2020. In Press. doi: doi.org/10.1016/j.ijantimicag.2020.105949 .

7. Driggin E, Madhavan MV, Bikdeli B, Chuich T, Laracy J, Bondi-Zoccai G, et al. Cardiovascular Considerations for Patients, Health Care Workers, and Health Systems During the Coronavirus Disease 2019 (COVID-19) Pandemic. J Am Coll Cardiol 2020 Mar 18 [Online ahead of print]. doi: 10.1016/j.jacc.2020.03.031.

8. Li W, Shi Z, Yu M, Ren W, Smith C, Epstein JH, et al. Bats are natural reservoirs of SARS-like coronaviruses. Science. 2005; 310(5748):676-9. doi: 10.1126/science. 1118391.
9. Lau SK, Woo PC, Li KS, Huang Y, Tsoi HW, Wong BH, et al. Severe acute respiratory syndrome coronavirus-like virus in Chinese horseshoe bats. Proc. Natl. Acad. Sci. 2005; 102(39):14040-5. doi: 10.1073/pnas.0506735102.

10. Fundação Oswaldo Cruz (FIOCRUZ) [homepage na internet]. Covid-19: Fiocruz Amazônia conclui o primeiro sequenciamento do vírus na região Norte

[acesso em 31 mar 2020]. Disponível em: https://portal. fiocruz.br/noticia/covid-19-fiocruz-amazonia-conclui-oprimeiro-sequenciamento-do-virus-na-regiao-norte.

11. Benvenuto D, Giovanetti M, Ciccozzi A, Spoto S, Angeletti S, Ciccozzi M. The 2019凶new coronavirus epidemic: Evidence for virus evolution. J Med Virol. 2020;1-5. doi: 10.1002/jmv.25688.

12. Yang $X, Y u Y, X u$ J, Shu $H$, Xia J, Liu H, et al. Clinical course and outcomes of critically ill patients with SARSCoV-2 pneumonia in Wuhan, China: a single-centered, retrospective, observational study. Lancet Respir Med 2020. doi: 10.1016/S2213-2600(20)30079-5.

13. Guan W, Ni Z, Hu Y, Liang W, Ou C, He J, et al. Clinical characteristics of coronavirus disease 2019 in China. The new england journal of medicine. 2020. doi: 10.1056/ NEJMoa2002032.

14. Fang L, Karakiulakis G, Roth M. Are patients with hypertension and diabetes mellitus at increased risk for COVID-19 infection?. The Lancet Respiratory Medicine. 2020. doi:10.1016/s2213-2600(20)30116-8.

15. Day M. Covid-19: European drugs agency to review safety of ibuprofen. BMJ 2020;368:m1168. doi: 10.1136/ bmj.m1168.

16. Day M. Covid-19: ibuprofen should not be used for managing symptoms, say doctors and scientists. BMJ. 2020;368:m1086. doi: 10.1136/bmj.m1086.

17. Instituto de Ciência Tecnologia e Qualidade (ICTQ) [homepage na internet]. OMS volta atrás sobre restrição de ibuprofeno no tratamento do coronavírus [acesso em 27 mar 2020]. Disponível em: https://www.ictq.com.br/ farmacia-clinica/1288-oms-volta-atras-sobre-restricaode-ibuprofeno-no-tratamento-do-coronavirus 
18. Ministério da Saúde [homepage na internet]. Uso da Cloroquina como terapia adjuvante no tratamento de formas graves do COVID-19 [acesso em 29 mar 2020]. Disponível em: https://cdn.oantagonista.net/ uploads/2020/03/nota_cloroquina.pdf

19. Touret $F$, Lamballerie $X$. Of chloroquine and COVID-19. Antiviral Res. 2020. doi: 10.1016/j. antiviral.2020.104762 